Reply

\section{Response to Commentary by Giuseppe Mancia}

\author{
Alexander C. Fanaroff, Renato D. Lopes *
}

Division of Cardiology, Duke Clinical Research Institute, Duke University Medical Center, 200 Morris St., Durham, NC 27701, USA

* Correspondence: Renato D. Lopes, Email: renato.lopes@duke.edu; Tel.: +1-919-668-7845.

We appreciate the commentary by Prof. Mancia on our manuscript [1]. He argues that randomized trials are not feasible to certain areas, particularly epidemiology, diagnosis, and patients' follow-up [2]. We agree that in the current climate, randomized trials of such topics are not feasible. However, all observational studies are subject to confounding; there are numerous examples in the literature of observational studies or expert opinion being contradicted by the results of well-conducted randomized clinical trials [3,4]. Acquiescing to the status quo, accepting that clinical trials are expensive and difficult to conduct, and lowering our standards for highquality evidence will not provide patients and physicians with the quality evidence they deserve to make decisions about their healthcare.

Rather, we believe our manuscript should serve as the impetus to revamp the clinical trials enterprise such that questions of importance to physicians and patients can be answered by rapid, less expensive randomized clinical trials, and that the importance of the question to patients' health should primarily drive decisions to conduct trials, rather than only the likelihood of the trial returning a positive return on investment to an industry funding partner [5]. The potential trials Prof. Mancia describes-examining frequency of follow-up for patients with hypertension, methods of screening for hypertension and assessing cardiovascular risk-have the potential to tremendously affect global health and resource utilization, and should not be dismissed as unfeasible.

Routine digital collection of healthcare data is creating an environment where, with coordination, pragmatic clinical trials should be able to be conducted with limited investment in data collection, enabling rapid, less costly evidence generation from randomized clinical trials. Registry-based clinical trials in Sweden, which leverage data collected for quality improvement and administrative purposes, have successfully enrolled high proportions of eligible patients in pragmatic clinical trials such as oxygen versus no oxygen in patients with acute myocardial infarction [6]. These types of trials should serve as a model for the rest of the world, and a call for governments to invest in high-quality, comprehensive, longitudinal, real-world data sources to which investigators can apply randomization. Further, by enrolling patients in trials during the course of routine practice and limiting patients' trial-specific contact with 
investigators, such pragmatic clinical trials also afford an opportunity to study therapeutic inertia and adherence with medications [7].

With the advent of digital data, there is a tremendous opportunity to reshape a portion of the clinical trials enterprise to put patients' needs at the center. Physicians and clinical trialists should think not of what evidence can be generated, but what evidence should be generated.

\section{CONFLICTS OF INTEREST}

Alexander C. Fanaroff is supported by a career development grant from the American Heart Association (17FTF33661087) and reports research grants from Boston Scientific. Renato D. Lopes reports research grants from Bristol-Myers Squibb, GlaxoSmithKline, Medtronic, Pfizer, and Sanofi; and personal fees from Amgen, Bayer, Boehringer Ingelheim, Bristol-Myers Squibb, GlaxoSmithKline, Medtronic, Pfizer, and Sanofi. This correspondence received no external funding.

\section{REFERENCES}

1. Fanaroff AC, Califf RM, Windecker S, Smith SC, Lopes RD. Levels of evidence supporting American College of Cardiology/Americah Heart Association and European Society of Cardiology Guidelines, 2008-2018. JAMA. 2019;321:1069-80.

2. Mancia G. Commentary on Fanaroff et al., Levels of Evidence Supporting American College of Cardiology/American Heart Association and European Society of Cardiology Guidelines, 2008-2018. JAMA. 2019;321(11):1069-80. Med One. 2019;4:e190008.

3. Lee IM, Cook NR, Gaziano JM, Gordon D, Ridker PM, Manson JE, et al. Vitamin $\mathrm{E}$ in the primary prevention of cardiovascular disease and cancer: the Women's Health Study: a randomized controlled trial. JAMA. 2005;294:56-65.

4. Echt DS, Liebson PR, Mitchell LB, Peters RW, Obias-Manno D, Barker AH, et al. Mortality and morbidity in patients receiving encainide, flecainide, or placebo: the Cardiac Arrhythmia Suppression Trial. N Engl J Med. 1991;324:781-88.

5. Califf RM, Robb MA, Bindman AB, Briggs JP, Collins FS, Conway PH, et al. Transforming evidence generation to support health and health care decisions. N Engl J Med. 2016;375:2395-400.

6. Hofmann R, James SK, Jernberg T, Lindahl B, Erlinge D, Witts N, et al. Oxygen therapy in suspected acute myocardial infarction. $N$ Engl $\mathrm{J}$ Med. 2017;377:1240-9.

7. Wang TY, Kaltenbach LA, Cannon CP, Fonarow GC, Choudhry NK, Henry TD, et al. Effect of Medication Co-payment Vouchers on P2Y12 Inhibitor Use and Major Adverse Cardiovascular Events Among Patients With Myocardial Infarction: The ARTEMIS Randomized Clinical Trial. JAMA. 2019;321:44-55.

How to cite this article:

Fanaroff AC, Lopes RD. Response to Commentary by Giuseppe Mancia. Med One. 2019;4:e190010. https://doi.org/10.20900/mo.20190010 